\title{
Assessing public commitment to endangered species protection: A Canadian case study
}

\author{
J.L. McCune ${ }^{a \star \dagger}$, Anja M. Carlsson ${ }^{\mathrm{b}}$, Sheila Colla ${ }^{\mathrm{c}}$, Christina Davy ${ }^{\mathrm{d} \varsigma}$, Brett Favaro ${ }^{\text {ef }}$, Adam T. Ford ${ }^{\mathrm{a} \ddagger}$, \\ Kevin C. Fraser ${ }^{\mathrm{g}}$, and Eduardo G. Martins ${ }^{\mathrm{h}}$ \\ ${ }^{a}$ Department of Integrative Biology, University of Guelph, Guelph, ON N1G 2W1, Canada; ${ }^{b}$ Department \\ of Ecosystem and Public Health, Faculty of Veterinary Medicine, University of Calgary, Calgary, AB T3R 1J3, \\ Canada; ${ }^{c}$ Faculty of Environmental Studies, York University, Toronto, ON M3J 1P3, Canada; ${ }^{\mathrm{d}}$ Natural \\ Resources DNA Profiling and Forensics Centre, Trent University, Peterborough, ON K9L 1Z8, Canada; \\ ${ }^{\text {e}}$ School of Fisheries, Fisheries and Marine Institute of Memorial University of Newfoundland, St. John's, \\ NL A1C 5R3, Canada; ${ }^{f}$ Department of Ocean Sciences, Memorial University of Newfoundland, Logy Bay, \\ NL A1C 5S7, Canada; ${ }^{g}$ Department of Biological Sciences, University of Manitoba, Winnipeg, MB R3T 2N2,

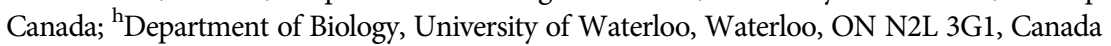 \\ *jenny.mccune@glel.carleton.ca \\ 'Current address: Geomatics and Landscape Ecology Research Laboratory, Department of Biology, Carleton \\ University, Ottawa, ON K1S 5B6, Canada. \\ 'Current address: Wildlife Research \& Monitoring Section, Ontario Ministry of Natural Resources \\ \& Forestry, Peterborough, ON K9J 7B8, Canada. \\ ${ }^{\ddagger}$ Current address: Department of Biology, University of British Columbia, Okanagan Campus, Kelowna, \\ BC V1V 1V7, Canada.
}

\section{Abstract}

Preventing the extinction of species will require limiting human activities in key areas, but it is unclear to what extent the public is committed to these limits and the associated costs. We commissioned an online survey of 1000 Canadians and asked them if it is important to prevent the extinction of wild species in Canada. We used specific scenarios illustrating the need for limits to personal activities, private property rights, and industrial development to further test their support. The respondents were strongly committed to species conservation in principle ( $89 \%$ agree), including the need to limit industrial development ( $80 \%$ agree). There was less support for limiting private property rights (63\% agree), and more uncertainty when scenarios suggested potential loss of property rights and industry-based jobs. This highlights the high level of public concern regarding the economic impacts of preventing extinctions, and the need for more programs to encourage voluntary stewardship of endangered species on private land. Opinion polls that measure public support for conservation without acknowledging the concessions required may result in overly optimistic estimates of the level of support. Most Canadians in our sample supported endangered species conservation even when the necessity of limiting human activities was explicitly stated.

Key words: Canada, conservation, endangered species, opinion poll, public opinion, online survey 


\section{Introduction}

As the global human population approaches eight billion, there is growing concern about the rate of extinction of other species that inhabit our planet (Barnosky et al. 2011; Dirzo et al. 2014). Compelling evidence points to humans as the direct or indirect cause of most modern extinctions. For example, in Canada over 700 species of plants and animals are at risk of extinction (Government of Canada 2015). The primary threats to these species include residential and commercial development; overexploitation via fishing, hunting, or collecting; disturbance by humans during work and recreational activities; pollution; and the introduction of exotic species (Venter et al. 2006; Prugh et al. 2010; McCune et al. 2013). It is clear that preventing the extinction of species will require limiting or excluding human activities in some areas.

It is not clear to what extent the public is committed to these limits. For example, national public opinion polls have repeatedly asked Canadians whether preserving endangered species is important, and between $82 \%$ and $97 \%$ of respondents agree that this is somewhat or very important to them (Gray et al. 1993; Ipsos Reid 2012). However, it is not known whether this strong support for conserving endangered species in principle would be maintained when the necessary concessions to commercial and personal activities are made clear. It is important to gauge the depth of citizens' commitment to endangered species conservation because of its bearing on public policy. If concern for endangered species is wide, but not deep, policy-makers may be hesitant to enact measures to address the issue beyond those that are mainly symbolic (Schrecker 2001). In Canada, recent widespread reduction in the scope of environmental law and incomplete implementation of policies meant to protect endangered species have led to protests by conservation scientists and practitioners in the media, in the scientific literature, and in the courts (Mooers et al. 2010; Otto et al. 2013; Favaro et al. 2014; Kirchhoff and Tsuji 2014; McDevitt-Irwin et al. 2015). This failure to fully implement laws to protect endangered species may reflect a lack of public commitment to conservation of species at risk. If this is true, conservation biologists and environmental activists have work to do to convince Canadians of the merits of bearing the costs of conservation.

We commissioned a nationwide public opinion poll to determine the depth of Canadians' support for measures to prevent the extinction of endangered species in Canada. We asked respondents about the importance of conserving endangered species in general, and we also probed the depth of their support using specific scenarios illustrating the need for limits to personal activities, private property rights, and industrial development. In addition, we asked these scenario-based questions in two ways: one from a "conservation" standpoint, which emphasized the need to conserve species; and the other from a "utilitarian" standpoint, which emphasized the rights of landowners and industry to utilize resources. In this way, we were able to measure how strongly Canadians' support for necessary actions holds up in the face of rhetoric that frames the issue as a matter of competing priorities, such as between endangered species conservation and economic development. Our objectives were to investigate: (1) to what extent Canadians support conservation of endangered species in Canada, and whether the level of support is correlated with demographic characteristics; (2) whether the level of commitment to conservation drops when respondents are confronted with a specific scenario outlining the need to limit human activities; (3) whether people respond to scenario questions differently depending on the way the scenario is presented; (4) whether there is a gap between general support and support given a specific scenario, and if this difference is correlated with demographic factors; and (5) how Canadians perceive the current level of spending on species conservation by the Federal Government.

\section{Materials and methods}

We commissioned the market research company Ipsos Reid to survey 1000 Canadians online. Ipsos Reid is Canada's largest market research firm, and their national online panel of over 200000 
members allows them to quickly reach and survey a large, diverse sample of Canadians without the need to send out paper surveys and reminders in the mail. The panel is updated regularly and nonrespondents are removed. Ipsos Reid collects demographic data from all panel participants, including gender, age, level of education, province of residence, income level, and whether the person has children or not. Online panels are a robust way to collect survey data and have been shown to generate findings that are as accurate as traditional telephone-based surveys (Schaffner 2014). We designed a survey with 12 questions (Table 1), based on previous polls on this subject (e.g., Gray et al. 1993; Czech and Krausman 1999; Harshaw 2008; Ipsos Reid 2012), experience during in-person interviews with landowners in Ontario (Olive and McCune 2017), and our study objectives.

Ipsos invited 13925 panel members to complete the survey, which was administered as part of a larger omnibus survey featuring additional questions on various other topics before or after our series of questions. These members were selected randomly but stratified to match the demographics of the general adult population of Canada. Panel members are regularly invited to complete surveys on multiple subjects, including market research and advertising, and they receive points for completing surveys that can be redeemed for consumer items, gift cards, or donations to charity. Therefore, even respondents with little or no interest in endangered species had incentive to complete the survey. Members log in to their account and there they can complete the survey. The survey was completed between 4 and 6 August 2015 by a total of 1004 respondents; a response rate of $7.21 \%$ over the $3 \mathrm{~d}$ period. Because the desired sample size was reached, no further invitations or reminders were sent out. The drop-out rate for the omnibus survey was approximately $10 \%$ overall and no one question was identified as a primary drop-out point. Ipsos Reid implemented the survey and data collection and provided the anonymized results to the authors. The sample of respondents who answered our survey included wide geographic and demographic representation (Table 2). Because all respondents had agreed to join the Ipsos online panel, we considered their consent to participate to be explicit. All Ipsos online panel members are informed that participation in all surveys is voluntary, and they can opt out of any survey at any time prior to submitting their response. Therefore, consent was implied when each respondent clicked the final "submit" button at the end of the survey. In addition, all data were analyzed anonymously. The research protocol and consent procedures were reviewed and approved by the Research Ethics Boards at the University of Guelph (\#15AP001), Trent University (\#24002), and the University of Waterloo (\#20785).

We designed the survey with two major goals in mind. First, we assessed each respondent's general support for endangered species conservation through level of agreement with broad statements. For example, "It is important to prevent the extinction of wild plants and animals in Canada" and "Landowners have a moral obligation to not harm endangered plants and animals on their property" (Table 1). Second, we tested whether the level of support for conservation remained consistent when respondents considered three specific scenarios in which they might be inconvenienced by endangered species conservation or endangered species laws. These scenarios involved personal interactions with endangered species, limits to private property rights, and limits to industrial development (Table 1).

To assess how the presentation of conservation needs affected support for biodiversity conservation, each scenario was presented in two ways. Respondents were randomly assigned to either version A or B of the survey (Table 1). Version A represents a "conservation" point of view, emphasizing the needs of threatened species. In this version, "strongly agree" or "somewhat agree" reflects a proconservation point of view. Version B represents a "utilitarian" point of view, emphasizing landowner rights and the potential for conservation to slow development or economic growth. In this version, "strongly disagree" or "somewhat disagree" represents a pro-conservation point of view. We reversed the scale for version $\mathrm{B}$ during analyses to directly compare answers from the two versions and determine whether the level of support for endangered species conservation differed depending on the way questions were framed. It has been demonstrated in the literature that the way a question is framed 
Table 1. The survey questions. For questions 1 through 8, the respondents were asked "Please indicate the extent to which you agree or disagree with each of the following statements”. Response options: strongly disagree; somewhat disagree; neither agree nor disagree; somewhat agree; strongly agree; don't know; prefer not to answer.

Topic Question

1. It is important to prevent the extinction of wild plants and animals in Canada. Individual encounters

2. Landowners have a moral obligation to not harm endangered plants and animals on their property.

3a. The Jefferson salamander is endangered, and only found in a few locations in Canada. If a landowner finds a Jefferson salamander on his or her property, they should leave it alone and not harm it.

3b. A landowner should have the right to capture, move or remove any plant or animal he or she encounters on his or her property, even if this could result in destroying the plant or animal in the process.

\section{Private property}

4. It is necessary for the government to put limits on private property rights to protect endangered plants and animals.

5a. The red mulberry is one of the most endangered trees in Canada, found at only 21 sites in southern Ontario. If a landowner has red mulberry trees on their property, they should not be permitted to build new buildings, create new trails, or do any other activity on their land if it involves cutting down or harming the trees.

5b. The red mulberry is one of the most endangered trees in Canada, found at only 21 sites in southern Ontario. Despite this, it would be unfair to restrict a landowner's ability to build new buildings, create new trails, or otherwise develop his or her property simply because red mulberry trees are growing there, and may need to be cut down in the process.

\section{Industrial development}

6. It is necessary for the government to prevent industrial development in certain areas to protect endangered plants and animals.

7a. The greater sage grouse is a bird that lives in the grasslands of southern Alberta and Saskatchewan. There are only about 150 sage grouse left in Canada, although there are many more birds in the US. Research has shown that the sage grouse cannot mate and raise their young successfully in areas near active oil wells. The federal government recently issued an emergency order to restrict construction and loud industrial noise in part of the remaining habitat of the sage grouse. The OR government is on the right track in limiting industrial activities in this area in an effort to save the sage grouse.

The greater sage grouse is a bird that lives in the grasslands of southern Alberta and Saskatchewan. There are only about 150 sage grouse left in Canada, although there are many more birds in the US. Research has shown that the sage grouse cannot mate and raise their young successfully in areas near active oil wells. However, given the economic importance of the oil industry in Canada, especially the thousands of jobs it provides, it makes sense to continue with oil well development even if it means that no sage grouse can survive in Canada.

\section{Government expenditures}

8. I support tax dollars being spent on protecting endangered plants and animals in Canada.

9. Who do you think should take primary responsibility for preventing the extinction of endangered plants and animals in Canada? (a) The federal government; (b) Provincial government; (c) Municipal government; (d) Environmental non-government organizations (NGOs); (e) Private business; (f) Individuals/landowners; (g) Prefer not to answer.

10. The Canadian federal government reports that since 2006 over $\$ 500$ million has been spent to protect Canada's diverse species. This amounts to approximately $\$ 2$ per Canadian per year. Do you think this amount is: (a) Not enough; (b) About the right amount; (c) Too much; (d) Prefer not to answer.

11. In your opinion, how much money should the federal government spend on protecting endangered plants and animals in Canada? Please enter the amount you think should be spent per Canadian per year on protecting endangered plants/animals. If you don't think any money should be spent on this, please enter " 0 ". [NUMERICAL RESPONSE-ENTER DOLLAR AMOUNT FROM 0]; or Prefer not to answer.
Agreement in principle with conservation of endangered species.

Agreement in principle with responsibility of individuals not to harm endangered species.

Agreement with a specific scenario involving personal encounter with an endangered species (conservation).

Agreement with idea that landowners are able to control species found o their property at their discretion (utilitarian).

Agreement in principle with the need for regulations of private property use.

Agreement with a specific scenario involving development of private property (conservation).

Agreement with alternative view of the same scenario (utilitarian).

Agreement in principle with the need for regulation of industrial development.

Agreement with a specific scenario involving regulation of industry (conservation).

Agreement with an alternative view on the same scenario (utilitarian).

Agreement in principle with the need for public funding for endangered species protection

Who Canadians think should take the lead in endangered species conservation.

Canadians' perception of federal spending for protecting endangered species.

Canadians' perception of federal spending-open-ended question 
Table 2. Demographic factors and the proportion of respondents in each group, compared with data from the 2011 Canadian Census.

\begin{tabular}{|c|c|c|c|c|c|}
\hline Factor & Group & $\begin{array}{l}\text { Proportion in survey } \\
\text { sample overall }\end{array}$ & $\begin{array}{l}\text { Proportion of survey } \\
\text { sample, version A }\end{array}$ & $\begin{array}{l}\text { Proportion in survey } \\
\text { sample, version B }\end{array}$ & $\begin{array}{c}\text { Proportion in } \\
\text { Canadian population } \\
\text { (2011 census) }\end{array}$ \\
\hline \multirow[t]{2}{*}{ Gender } & Male & 47.8 & 47.4 & 48.2 & 49.0 \\
\hline & Female & 52.2 & 52.6 & 51.8 & 50.9 \\
\hline \multirow[t]{4}{*}{$\operatorname{Age}^{a}$} & $18-24$ years & 8.4 & 8.8 & 8.0 & 11.6 \\
\hline & $25-49$ years & 44.1 & 43.2 & 45.0 & 43.3 \\
\hline & $50-74$ years & 42.2 & 42.2 & 42.2 & 36.6 \\
\hline & 75 years or older & 5.3 & 5.8 & 4.8 & 8.5 \\
\hline \multirow[t]{4}{*}{ Education level } & High school or less & 25.8 & 23.9 & 27.7 & 35.9 \\
\hline & $\begin{array}{l}\text { University/College/Trades } \\
\text { certificate }\end{array}$ & 41.4 & 42.0 & 40.8 & 38.3 \\
\hline & Bachelor's degree & 23.6 & 24.5 & 22.7 & 16.5 \\
\hline & $\begin{array}{l}\text { Graduate degree (master's, } \\
\text { PhD, medical) }\end{array}$ & 9.2 & 9.6 & 8.8 & 9.4 \\
\hline \multirow[t]{13}{*}{ Province } & British Columbia & 12.3 & 11.2 & 13.4 & 13.1 \\
\hline & Alberta & 10.3 & 11.0 & 9.6 & 10.9 \\
\hline & Saskatchewan & 3.2 & 4.0 & 2.4 & 3.1 \\
\hline & Manitoba & 5.2 & 5.4 & 5.0 & 3.6 \\
\hline & Ontario & 36.2 & 37.3 & 35.1 & 38.4 \\
\hline & Quebec & 23.1 & 20.9 & 25.3 & 23.6 \\
\hline & New Brunswick & 3.5 & 5.0 & 2.0 & 2.2 \\
\hline & Nova Scotia & 4.1 & 3.0 & 5.2 & 2.8 \\
\hline & Prince Edward Island & 0.2 & 0.4 & 0 & 0.4 \\
\hline & Newfoundland and Labrador & 2.1 & 2.0 & 2.2 & 1.5 \\
\hline & Yukon & 0 & 0 & 0 & 0.1 \\
\hline & Northwest Territories & 0 & 0 & 0 & 0.1 \\
\hline & Nunavut & 0 & 0 & 0 & 0.1 \\
\hline \multirow[t]{4}{*}{ Household income } & Less than $\$ 35$ 000/year & 22.5 & 22.7 & 22.3 & 15.2 \\
\hline & $\$ 35000-\$ 74999$ & 30.3 & 30.1 & 30.5 & 31.5 \\
\hline & $\$ 75000-\$ 149999$ & 28.8 & 29.9 & 27.7 & 37.5 \\
\hline & More than $\$ 150000$ & 18.4 & 17.3 & 19.5 & 15.8 \\
\hline \multirow[t]{2}{*}{ Have children } & No children & 75.4 & 75.3 & 75.5 & Unknown $^{b}$ \\
\hline & Children & 24.6 & 24.7 & 24.5 & Unknown $^{b}$ \\
\hline \multirow[t]{3}{*}{ Own $>5$ acres of land } & Yes & 8.0 & 6.8 & 9.2 & Unknown \\
\hline & No & 90.4 & 91.0 & 89.8 & Unknown \\
\hline & Prefer not to answer & 1.6 & 2.2 & 1.0 & Unknown \\
\hline
\end{tabular}

${ }^{a}$ Age is calculated as a proportion of people aged 18 and over, because we did not survey people under 18 years of age.

${ }^{b}$ According to the 2011 Census, $61.2 \%$ of households in Canada did not include children under 24 years of age. 
can affect the response (e.g., Gendall and Hoek 1990; Nelson and Oxley 1999). We used this wellknown phenomenon to test the stability of the public's stated support for endangered species conservation. Respondents selected to answer version A were asked the conservation version of all three scenario questions, whereas respondents selected to answer version B were asked the utilitarian version of all three scenario questions.

Public concern for endangered species is often greater for more charismatic, larger, or more attractive species (e.g., polar bears), whereas concern for unknown or potentially dangerous species (e.g., snakes) may be lower (Kellert 1996; Lorimer 2007; Knight 2008). For this reason, we carefully chose species to use in the scenarios that were neither particularly adored nor feared by the Canadian public, including a salamander, a tree, and a bird. To identify respondents who were owners of land that could potentially support habitat for one or more endangered species, we asked respondents whether they owned more than 5 acres of land. Although various wild species can undoubtedly be found on smaller parcels, we chose the threshold of 5 acres ( 2 ha) to exclude landowners who own only small parcels in urban or suburban areas.

We also asked respondents who they thought should be responsible for biodiversity conservation, and three questions about the amount of money that the federal government allocates to endangered species conservation. We first asked respondents if they agreed in principle with the expenditure of tax dollars for protecting endangered plants and animals in Canada (question 8, Table 1). We then asked whether actual federal expenditures over the past 5 years, as reported by the federal government itself, are too little, about right, or too much (question 10, Table 1). Finally, we asked respondents what they thought the federal government should spend in an open-ended question (question 11, Table 1). Our purpose was not to determine a dollar amount for public willingness to pay for endangered species conservation. Estimating this would require a detailed contingent valuation study (e.g., Richardson and Loomis 2009), and even this method has been questioned (e.g., Hausman 2012). Rather, we simply aimed to measure both the level of agreement with the principle that the government should contribute money for species conservation, and respondents' perception of the current spending amount.

\section{Analyses}

First, we tested whether there was a significant difference in the response between the two different versions of the survey for all questions, including the questions that were phrased identically in both versions. We used cumulative logit models (CLMs) with level of agreement as the response and the survey version as the predictor. CLMs take into account the explicit ordering of the categorical response variable without assuming that the distance between classes is constant (Agresti 2002). We then tested whether any of the seven demographic variables, including land ownership, were significant predictors of respondents' level of agreement with each statement. If there was a significant effect of survey version, we analyzed each version separately. In all tests, we first removed the few respondents who had selected "don't know" or "prefer not to answer" (less than $6 \%$ of respondents for all questions). Then, for each question, we built a CLM including all seven demographic factors and tested the significance of each factor using marginal fitting of terms based on a $\chi^{2}$ test. We did not include interactions because we did not have any a priori reason to expect specific interactions between demographic factors. The demographic variables were minimally intercorrelated, with the strongest correlation between respondent age and having children (Pearson's $r=0.29$ ). For details of CLM analysis, see Supplementary Material 1.

To measure the change in agreement from the general statements (statements 2,4 , and 6 , Table 1 ) to the corresponding scenario questions (statements 3,5 , and 7), we divided respondents who agreed with the general statement into four categories: those who still agreed with the corresponding scenario statement (i.e., remained pro-conservation), those who switched to a pro-utilitarian answer, those 
who switched to a non-committal "neither agree nor disagree" (i.e., they were no longer sure), and those who switched to "don't know" or "prefer not to answer". We then used Fisher's exact tests to determine whether membership in these four categories was associated with differences in each demographic variable.

We also used CLMs to examine whether general support for tax dollars going to endangered species conservation and perception of the current amount of government funding for species protection were predictable based on demographic factors. We completed all analyses in $\mathrm{R}$ ( $\mathrm{R}$ Core Team 2013), using the "ordinal" package for building CLMs (Christensen 2015). The raw data are available in Supplementary Material 2.

\section{Results}

\section{Support for conservation in principle}

Eighty-nine percent of respondents somewhat or strongly agreed that it is important to prevent the extinction of wild plants and animals in Canada (Fig. 1). There was also strong agreement with a landowner's moral obligation not to harm endangered species (82\% agree) and the need for limits to industrial activity to protect endangered species (80\% agree; Fig. 1). A smaller majority of respondents agreed with the need for government to put limits on private property rights (63\%; Fig. 1).

The only demographic factor that affected the response to question 1 was gender. Females were about 1.36 times more likely than males to give a more pro-conservation response (Table 3 ). Female

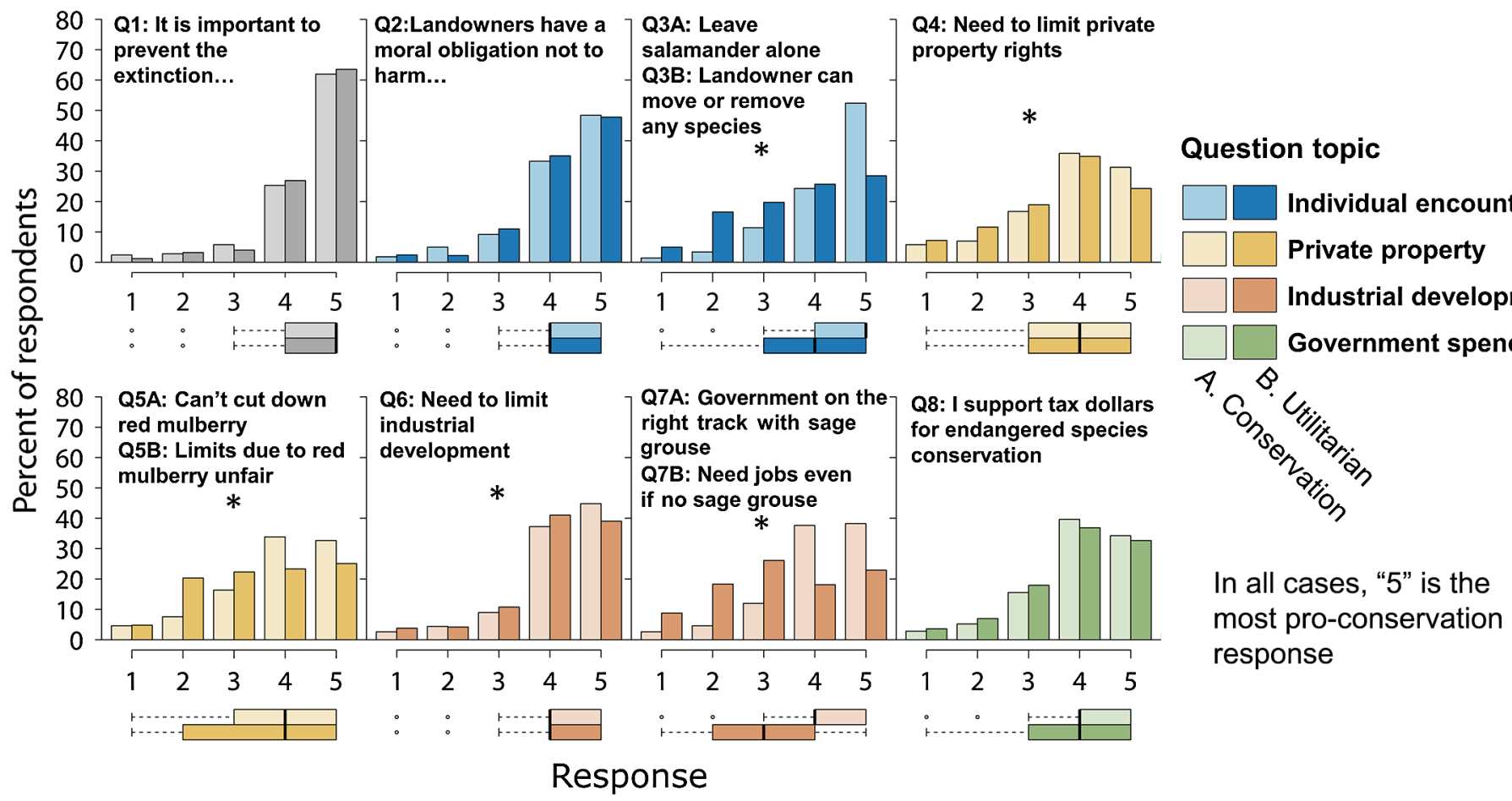

Fig. 1. Responses to each survey question by survey version. Response is as follows: 1 -strongly disagree (or strongly agree with utilitarian scenario), 2 -somewhat disagree (or somewhat agree with utilitarian scenario), 3-neither agree nor disagree, 4-somewhat agree (or somewhat disagree with utilitarian scenario), 5-strongly agree (or strongly disagree with utilitarian scenario). Respondents who answered "don't know" or "prefer not to answer" have been removed (less than $6 \%$ of respondents in all cases). Asterisks indicate a significant difference in the response between versions A and B according to cumulative logit models. 
Table 3. Results of cumulative logit models including all demographic factors. A and B survey groups were tested separately only if there was a significant difference in response between versions.

\begin{tabular}{|c|c|c|c|c|c|c|c|}
\hline Question & Gender & Age & Education & Province & Income & Kids/no kids & Own land? \\
\hline $\begin{array}{l}1 \text { (pooled) } \\
N=976\end{array}$ & $\begin{array}{l}\boldsymbol{p}=\mathbf{0 . 0 2 5} \\
(\text { female } 1.36)\end{array}$ & $p=0.875$ & $p=0.193$ & $p=0.144$ & $p=0.983$ & $p=0.197$ & $p=0.116$ \\
\hline $\begin{array}{l}2 \text { (pooled) } \\
N=972\end{array}$ & $\begin{array}{l}\boldsymbol{p}=\mathbf{0 . 0 0 2} \\
(\text { female } 1.48)\end{array}$ & $p=0.234$ & $p=0.989$ & $p=0.057$ & $p=0.413$ & $p=0.552$ & $p=0.086$ \\
\hline $\begin{array}{l}3 \text { (version A) } \\
N=458\end{array}$ & $p=0.311$ & $p=0.885$ & $p=0.990$ & $p=0.138$ & $p=0.887$ & $p=0.070$ & $p=0.104$ \\
\hline $\begin{array}{l}3 \text { (version B) } \\
N=475\end{array}$ & $\begin{array}{l}\boldsymbol{p}<\mathbf{0 . 0 0 1} \\
(\text { female } 1.85)^{a}\end{array}$ & $p=0.397$ & $\begin{array}{l}p=\mathbf{0 . 0 2 6} \\
\text { (graduate degree } 1.86 \\
\quad \text { compared with high } \\
\quad \text { school or less) }\end{array}$ & $\begin{array}{l}p=\mathbf{0 . 0 0 7} \\
\text { (Saskatchewan and } \\
\text { Manitoba } 0.45 \text { and } 0.43 \\
\text { compared with Alberta) }\end{array}$ & $p=0.451$ & $p=0.615$ & $\begin{array}{c}p=\mathbf{0 . 0 2 9} \\
\text { (no land } \\
1.92 \text { ) }\end{array}$ \\
\hline $\begin{array}{l}4 \text { (version A) } \\
N=476\end{array}$ & $p=0.094$ & $p=0.722$ & $p=0.921$ & $p=0.855$ & $p=0.690$ & $p=0.364$ & $p=0.865$ \\
\hline $\begin{array}{l}4 \text { (version B) } \\
N=481\end{array}$ & $p=0.712$ & $\begin{array}{l}\boldsymbol{p}=\mathbf{0 . 0 0 8} \\
\text { (all older age groups } \\
\quad 0.32 \text { compared with } \\
\text { age }<25 \text { ) }\end{array}$ & $\begin{array}{l}\boldsymbol{p}=\mathbf{0 . 0 1 7} \\
\text { (graduate degree } 2.45 \\
\text { compared with high } \\
\text { school or less) }\end{array}$ & $\begin{array}{l}\boldsymbol{p}<\mathbf{0 . 0 0 1} \\
\text { (Quebec } 2.41 \text { compared } \\
\quad \text { with Alberta) }\end{array}$ & $\begin{array}{l}p=\mathbf{0 . 0 2 2} \\
(>\$ 150 \mathrm{~K} 0.55 \\
\quad \text { compared with } \\
\quad<\$ 35 \mathrm{~K})\end{array}$ & $p=0.970$ & $\begin{array}{c}p=\mathbf{0 . 0 3 3} \\
\text { (no land } \\
1.87 \text { ) }\end{array}$ \\
\hline $\begin{array}{l}5 \text { (version A) } \\
N=468\end{array}$ & $p=0.099$ & $p=0.569$ & $p=0.489$ & $p=0.203$ & $p=0.506$ & $p=0.286$ & $p=0.871$ \\
\hline $\begin{array}{l}5 \text { (version B) } \\
N=476\end{array}$ & $p=0.280$ & $\begin{array}{l}\boldsymbol{p}=\mathbf{0 . 0 5 0} \\
(\text { age } 50-740.46 \text { compared } \\
\quad \text { with age }<25)\end{array}$ & $p=0.794$ & $p=0.136$ & $p=0.290$ & $p=0.119$ & $p=0.142$ \\
\hline $\begin{array}{l}6 \text { (version A) } \\
N=482\end{array}$ & $p=0.243$ & $p=0.491$ & $p=0.859$ & $p=0.119$ & $p=0.985$ & $p=0.514$ & $p=0.780$ \\
\hline $\begin{array}{l}6 \text { (version B) } \\
N=491\end{array}$ & $p=0.211$ & $\begin{array}{l}p=\mathbf{0 . 0 1 9} \\
(\text { age }>750.21 \text { compared } \\
\quad \text { with age }<25)\end{array}$ & $p=0.650$ & $p=0.490$ & $p=0.455$ & $p=0.065$ & $p=0.100$ \\
\hline $\begin{array}{l}7(\text { version } \mathrm{A}) \\
N=471\end{array}$ & $\begin{array}{l}\boldsymbol{p}=\mathbf{0 . 0 0 2} \\
(\text { female } 1.74)\end{array}$ & $p=0.587$ & $p=0.729$ & $p=0.116$ & $p=0.663$ & $p=0.985$ & $p=0.786$ \\
\hline $\begin{array}{l}7 \text { (version B) } \\
N=468\end{array}$ & $p=0.357$ & $p=0.791$ & $p=0.948$ & $p=0.587$ & $p=0.256$ & $p=0.051$ & $p=0.062$ \\
\hline $\begin{array}{l}8 \text { (pooled) } \\
N=968\end{array}$ & $p=0.243$ & $p=0.723$ & $p=0.224$ & $p=0.742$ & $p=0.258$ & $p=0.213$ & $p=0.220$ \\
\hline $\begin{array}{l}10(\text { version A) } \\
N=469\end{array}$ & $p=0.550$ & $p=0.493$ & $p=0.256$ & $p=0.384$ & $p=0.505$ & $p=0.136$ & $p=0.788$ \\
\hline $\begin{array}{l}10 \text { (version B) } \\
N=472\end{array}$ & $p=0.746$ & $p=0.124$ & $p=0.166$ & $p=0.403$ & $p=0.728$ & $p=0.566$ & $p=0.155$ \\
\hline
\end{tabular}

Note: $p$ values are based on $\chi^{2}$ tests, with significant tests $(p<0.05)$ in bold. Odds ratios are given in brackets for significant predictors. Barplots for significant factors are available in Supplementary Material 1.

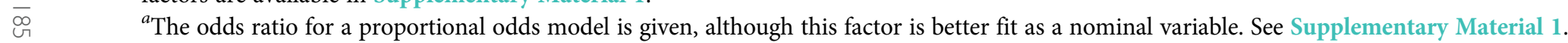


respondents were also more likely than males to agree that landowners have a moral obligation not to harm endangered species found on their property. For respondents answering the utilitarian version of the survey, opinions on the need for the government to put limits on private property rights were related to age, education level, province of residence, income level, and land ownership (Table 3). Respondents under the age of 25, those with graduate degrees, and those who did not own 5 acres or more of land were more likely to support this statement, as were lower income respondents. More respondents from Quebec strongly agreed (Table 3, Fig. S1). Respondents over the age of 75 answering the utilitarian survey version of question 6 were less likely to support the need to limit industrial development.

\section{Scenario questions}

The proportion of respondents giving pro-conservation answers declined slightly from the principle question to the conservation version of scenario questions, and declined more steeply for the utilitarian scenarios (Fig. 1). For example, when asked whether a landowner who finds an endangered salamander should leave it alone and not harm it (question 3a), 77\% agreed (Fig. 1). However, only $54 \%$ of respondents who were asked the "utilitarian" version (question $3 \mathrm{~b}$ ) gave a pro-conservation answer. The greatest shift occurred for the question about limits to industry. Most respondents $(80 \%)$ agreed that limiting industry is necessary, and $76 \%$ of respondents agreed that the government is on the right track in limiting the oil industry to protect the greater sage grouse (question $7 \mathrm{a}$ ). However, only $41 \%$ disagreed with the utilitarian view that oil industry jobs necessitate development, even if that means no greater sage grouse can survive in Canada (question 7b) (Fig. 1). The most common answer to this utilitarian scenario was "neither agree nor disagree" (26\%).

The way the three specific scenario questions were presented had a substantial impact on the response (Fig. 1). In addition, opinions about whether government should limit private property rights (question 4) or industrial development (question 6) differed slightly but significantly between respondents who had been primed with conservation scenarios (version A) versus utilitarian scenarios (version B). However, the survey version did not affect support for tax dollars going towards endangered species conservation, even though this question was asked after all three scenario questions (question 8; Fig. 1).

Some demographic factors were significant predictors of responses to scenario questions. For example, females were less likely to agree that landowners should be able to move or remove any species found on their property (females were about 1.85 times more likely to give a pro-conservation response; Table 3). A higher proportion of female than male respondents strongly agreed that the government is on the right track in limiting oil industry activities in a part of the range of the greater sage grouse. Landowners were more likely to agree that a landowner should be able to move or remove any species from his or her property (Table 3 ).

\section{Predicting shifts from general questions to scenarios}

Respondents who agreed (somewhat or strongly) with the general statements (questions 2, 4, or 6) were more likely to shift away from a pro-conservation viewpoint when confronted with a utilitarian scenario than those who were asked the conservation-oriented scenario (Fig. 2). However, individual demographic factors were associated with the nature of the shift in only three cases (Table S1).

\section{Government responsibility and expenditures}

Most respondents (60\%) agreed that the Federal Government should have primary responsibility for preventing the extinction of plants and animals in Canada. This was followed by environmental nongovernment organizations (13\%), Provincial Government (10\%), individuals or landowners (7\%), 


Q2. Landowners have a
moral obligation to not
harm...
A: $81.7 \%$ agree
B: $82.9 \%$ agree

Q4. It is necessary for the government to put limits on private property rights...

A: $67.1 \%$ agree

B: $59.2 \%$ agree

Q6. It is necessary for the government to put limits on industrial development...

A: $82.1 \%$ agree

B: $80.1 \%$ agree
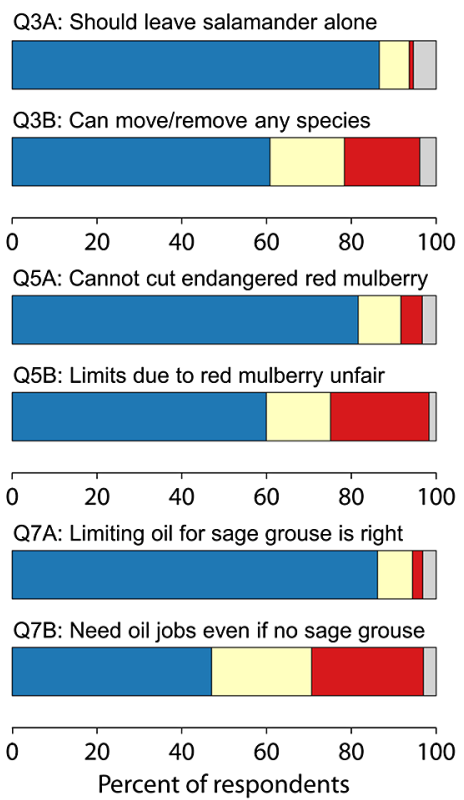

Fig. 2. Change in responses from each principle question to the corresponding scenario question only for respondents who agreed (somewhat or strongly) with the principle question. The shift in response was different between the two versions of the survey in all cases $(p<0.05)$. The colours are interpreted as follows: blue-maintained a proconservation response; $\tan -$ shifted to "neither agree nor disagree"; red-shifted to pro-utilitarian response; grey-shifted to "don't know" or "prefer not to answer".

Municipal Government (3\%), and private business (less than 1\%). About 7\% of respondents chose "prefer not to answer" for this question. The Government of Canada reportedly spent about 500 million dollars (\$2 per citizen per year) between 2006 and 2014 to protect Canada's endangered species (Environment Canada 2014). Forty-five percent of respondents said this is not enough, whereas $43 \%$ said this is "about right". Respondents who were asked the conservation version of the scenario questions were more likely to think that $\$ 2$ per citizen per year is not enough. Values provided in response to question 11 ranged from $\$ 0$ to $\$ 100000$, with 268 respondents selecting "prefer not to answer". Given that the current spending was provided (i.e., \$2.00 CAD per Canadian, per year), we suspect that values far greater than current spending reflected a misunderstanding of the question. Therefore, we report the median rather than mean values to avoid inflation by these few extreme outliers. The median amount entered by respondents who answered that current levels of spending are too low was $\$ 7.00 \mathrm{CAD}$ per Canadian, per year. The median for those answering "about right" was $\$ 2.00$, and the median for those answering "too much" was $\$ 0$. The median amount across all respondents was $\$ 5.00$, and this did not differ between the two versions of the survey.

\section{Discussion}

The majority of Canadians in our sample say they support the conservation of endangered species, and the need to make concessions both in principle and in practice to do so. At the same time, the divergence of responses to the two versions of the scenario questions highlights the internal dilemmas people face when weighing the costs and benefits of conserving species. Canadians are strongly committed to the principle of preventing extinction, but conservation scientists, policy-makers, and environmental advocates have more work to do to design policies and programs that will transform this commitment into action.

A strong majority $(\geq 80 \%)$ of respondents supported the principle of preventing extinctions in Canada, the moral obligation not to harm endangered species, and the need to prevent industrial development in some situations. The support for these principles was maintained even when respondents were confronted with specific conservation-oriented scenarios. Women were more likely than men to agree with the principle of preventing extinctions and the moral responsibility not to harm 
endangered species, which is consistent with other studies on gender and environmental attitudes (Kellert and Berry 1987). In general, Canadians of all ages, education levels, income levels, and from all provinces support the protection of endangered species and the need to limit industry to do so.

There was less support for the limitation of private property rights to protect endangered species. This finding is important because most of Canada's species at risk depend on privately owned land to some extent (Kerr and Deguise 2004). North Americans tend to hold a strong belief in the rights of landowners to manage their property as they see fit, without government interference (James 2002; Lovett-Doust et al. 2003; Raymond and Olive 2008). However, a distaste for outside intervention does not necessarily indicate unwillingness to protect endangered species-many landowners feel a responsibility to be good stewards, they just do not want to be regulated (Brook et al. 2003; Jackson-Smith et al. 2005; Raymond and Olive 2008). Therefore, the lower degree of support we found for the principle of regulating private property use compared with the need to prevent extinctions in general is not necessarily contradictory. However, it points to some gaps in research and policy.

In the US, the Endangered Species Act (ESA) took a strong regulatory approach to conservation on private lands. Numerous studies have highlighted the problems with this approach (e.g., Bean and Wilcove 1997; James 2002; Brook et al. 2003) and investigated the attitudes and values of private landowners in the US (e.g., Daley et al. 2004; Sorice et al. 2013). Partly in response to these negative lessons, Canada's Species at Risk Act (SARA) adopted a "stewardship first" strategy, whereby strong regulations are imposed only on federally owned land, with conservation on private land left to voluntary stewardship by landowners (Olive 2014). However, there has not been much attention paid to how willing landowners in Canada actually are to carry out stewardship on their property voluntarily. The few studies that have investigated this have found that most landowners say they are willing to steward, but they are often unaware of the endangered species that live in their region or what they can do to conserve them (Olive 2011; Quartuch and Beckley 2014; Olive and McCune 2017). Landowners express a desire for more incentive programs to defray the economic costs of habitat restoration and more education about what to do (Matthews et al. 1993; Sutherland 1997; Henderson et al. 2014). Environmental organizations in a few provinces have implemented successful programs to foster stewardship by private landowners (e.g., Sutherland 1997; Vinge-Mazer and Ranalli 2012), but efforts to support private land conservation across Canada are patchy and poorly funded. Our finding of less support overall for government regulation of private land supports the need for more programs that provide education and incentives to encourage voluntary stewardship by landowners.

When comparing questions in principle to scenarios, there was a greater drop in the proconservation response to the utilitarian version compared with the conservation version. We believe this is an example of how the level of support for a concept depends on the nature of the trade-offs presented (Gendall and Hoek 1990). Although the conservation-oriented scenarios presented the limitations that would be required in a specific case, the utilitarian versions directly introduced a conflict between endangered species protection and private property rights or economic development. For example, while the conservation version of the sage grouse scenario acknowledged the necessity of limiting oil development, the utilitarian version explicitly introduced the concept of a potential loss of jobs as a result. People often do not have static opinions on a given issue, and they show this uncertainty when faced with conflicts or alternative considerations (Zaller and Feldman 1992; Nelson and Oxley 1999). For this reason, we expected a drop in pro-conservation support for people presented with the utilitarian scenarios. But we were struck by the relatively high proportion of respondents who answered "neither agree nor disagree" to the utilitarian versions. We suspect that these respondents are those who need to know more details about the question before they can settle on their opinion. For example, under what circumstances would a landowner be 
prevented from cutting down an endangered red mulberry tree, and would compensation be available for the loss of development options? How many jobs might be lost due to limiting oil development for the greater sage grouse? We think the high number of undecided responses suggests the need for endangered species protection policies to be developed in close consultation with the public and stakeholders. If the necessary concessions and regulations are seen as clear and legitimate (Olive 2014), more people would settle on the pro-conservation side, in line with their strong support for species conservation in principle.

The identity of respondents who shifted from pro-conservation to pro-utilitarian views when confronted with the scenario questions was rarely associated with individual demographic factors. Indeed, the majority of respondents who gave a pro-conservation answer to the principle question maintained their pro-conservation stance in response to the related scenario question. In addition, while respondents of different age, gender, or from different provinces sometimes gave significantly different responses to particular questions (Table 3, Fig. S1), no single demographic factor was a consistent predictor of the level of support for endangered species conservation. Therefore, a broad approach to outreach is likely the most effective strategy for increasing support for endangered species conservation.

\section{Limitations of the study}

We acknowledge that our choice of species could have affected responses to the scenario questions. As noted above, we tried to choose species that are neither especially prized nor loathed by the Canadian public. However, it is possible that, for example, more people agreed that the government is on the right track in limiting development to protect the sage grouse (76\%) than those who agreed that a landowner should not be able to cut down an endangered red mulberry tree (67\%) because people care more about birds than trees, or because more people have heard about the sage grouse than the mulberry tree, rather than because people are less willing to support limitations of personal property rights than limitations to industrial development. However, given the responses to the corresponding principle questions, which did not involve a specific species, we do not think this is the case. Future surveys could test this by designing multiple scenarios with a wider range of species.

Our sample of respondents does not perfectly match the demographics of the Canadian population according to the 2011 census (Table 2). All categories except gender show significant differences $\left(\chi^{2}\right.$ tests; results not shown). However, responses to relatively few questions were significantly affected by demographic characteristics (Table 3), and we do not have reason to expect that our results are greatly biased one way or the other. For example, our sample has fewer respondents over age $75 \mathrm{com}$ pared with the national average (a group less likely to give a pro-conservation answer to some questions, see Table 3), but we also have fewer respondents aged 18-24 (a group more likely to give a pro-conservation answer to some questions). Our sample contained no respondents from the Yukon, the Northwest Territories, or Nunavut, so we cannot predict how the inclusion of people from these regions may have shifted the results.

There are many characteristics other than the demographic variables we tested that could influence a respondent's support for conservation of endangered species. For example, some studies have shown that people who participate in outdoor recreation activities such as hiking or birding are more likely to have pro-environment attitudes (e.g., Jackson 1986, but see Bjerke and Kleiven 2006 for an example that shows this is not always true). We did not collect data on these factors, and so we cannot say whether this was true for our sample, or whether our sample was biased towards or against those who participate in these recreational activities. Because the survey was administered online, our sample was limited to those who have internet access. According to a 2012 survey, 83\% of Canadian households had access to the internet at home; however, only $75 \%$ of households in rural areas had access (Statistics Canada 2013). 
Finally, respondents are limited by the survey format to the options provided for each response. For example, it is possible that some respondents may have preferred that the Federal and Provincial governments jointly take primary responsibility for preventing the extinction of endangered plants and animals in Canada, but this combination was not provided as a choice for the response.

\section{Conclusion}

Public opinions polls are regularly used to assess peoples' attitudes on important policy issues, but a poll can be misleading if it is designed for purposes of advocacy rather than description (Brown and Delodder 2003). We aimed to reveal the depth of Canadians' commitment to conserving endangered species by including questions that framed the issue from both a conservation and a utilitarian standpoint. By doing so, we were able to assess not only stated values, but also the stability of those values when faced with conflicting considerations.

Our results show that Canadians support the need to conserve species at risk of extinction. They are willing to make concessions both in principle and in practice and many perceive current government spending levels as too low. However, Canadians are worried about private property rights and unemployment. This underscores the need for more outreach and incentive programs for conservation on private land and for environmental legislation that is perceived as clear and legitimate. The status of species at risk around the world will not improve without a concerted effort to reduce anthropogenic threats. Surveys that go beyond statements of support in principle and probe willingness to make compromises in practice will better reflect the level of public support for conservation and highlight policy issues that require more public consultation and outreach.

\section{Acknowledgements}

A. Olive, N. Young, S. English and S. Otto provided helpful comments on survey design. S. Otto also provided thoughtful comments on an earlier draft of the manuscript. We thank Sarah English of Ipsos Reid for challenging us to frame questions from the utilitarian standpoint. Funding for the survey was provided by research funds from the Liber Ero program and research funds from the University of British Columbia to support Dr. Sarah Otto, Director of the Liber Ero program. Ipsos Reid was contracted by the authors to assist with study design and to carry out data collection. Ipsos Reid and the project funders were not involved in data analysis, decision to publish, or preparation of the manuscript. All opinions and data interpretation in this paper are the authors' and do not necessarily reflect the views of Ipsos Reid.

\section{Author contributions}

Conceived and designed the study: JLM, AMC, SC, CD, BF, ATF, KCF, EGM. Performed the experiments/collected the data: Ipsos Reid on behalf of JLM, AMC, SC, CD, BF, ATF, KCF, EGM. Analyzed and interpreted the data: JLM, BF, ATF, EGM. Contributed resources: JLM, AMC, SC, CD, BF, ATF, KCF, EGM. Drafted or revised the manuscript: JLM, AMC, SC, CD, BF, ATF, KCF, EGM.

\section{Competing interests}

$\mathrm{BF}$ is currently serving as a Subject Editor for FACETS, but was not involved in review or editorial decisions regarding this manuscript.

\section{Data accessibility statement}

All relevant data are within the paper and in the Supplementary Material. 


\section{Supplementary material}

The following Supplementary Material is available with the article through the journal website at doi:10.1139/facets-2016-0054.

Supplementary Material 1

Supplementary Material 2

\section{References}

Agresti A. 2002. Categorical data analysis. Wiley, New York, New York. 734 p.

Barnosky AD, Matzke N, Tomiya S, Wogan GOU, Swatzh B, Quental TB, et al. 2011. Has the Earth's sixth mass extinction already arrived? Nature, 471: 51-57. PMID:21368823. doi:10.1038/ nature09678.

Bean MJ, and Wilcove DS. 1997. The private-land problem. Conservation Biology, 11: 1-2.

Bjerke T, and Kleiven J. 2006. Outdoor recreation interests and environmental attitudes in Norway. Managing Leisure, 11: 116-128. doi:10.1080/13606710500520197.

Brook A, Zint M, and De Young R. 2003. Landowners' responses to an Endangered Species Act listing and implications for encouraging conservation. Conservation Biology, 17: 1638-1649. doi:10.1111/ j.1523-1739.2003.00258.x.

Brown SD, and Delodder J. 2003. When is a creationist not a creationist? Appreciating the miracles of public opinion polling. Canadian Journal of Communication, 28: 1-8.

Christensen RHB. 2015. ordinal-regression models for ordinal data. R package version 2015.6-28. [online]: Available from https://cran.r-project.org/web/packages/ordinal/.

Czech B, and Krausman PR. 1999. Research notes public opinion on endangered species conservation and policy. Society \& Natural Resources, 12: 469-479. doi:10.1080/089419299279542.

Daley SS, Cobb DT, Bromley PT, and Sorenson CE. 2004. Landowner attitudes regarding wildlife management on private land in North Carolina. Wildlife Society Bulletin, 32: 209-219. doi:10.2193/ 0091-7648(2004)32[209:LARWMO]2.0.CO;2.

Dirzo R, Young HS, Galetti M, Ceballos G, Isaac NJB, and Collen B. 2014. Defaunation in the Anthropocene. Science, 345: 401-406. PMID:25061202. doi:10.1126/science.1251817.

Environment Canada. 2014. 2014-15 Report on plans and priorities. Cat. No.: En1-49/2014E-PDF, ISSN: 2292-5694. [online]: Available from http://www.ec.gc.ca/default.asp?lang=En\&n=024B8406-1\&offset=3\& toc $=$ show.

Favaro B, Claar DC, Fox CH, Freshwater C, Holden JJ, Roberts A, et al. 2014. Trends in extinction risk for imperiled species in Canada. PLoS ONE, 9: e113118. PMID:25401772. doi:10.1371/journal. pone.0113118.

Gendall P, and Hoek J. 1990. A question of wording. Marketing Bulletin, 1: 25-36.

Government of Canada. 2015. Wildlife species search. Species at Risk Public Registry [online]: Available from https://www.registrelep-sararegistry.gc.ca/search/SpeciesSearch_e.cfm. 
Gray A, Boxall P, Reid R, Filion FL, DuWors E, Jacquemot A, et al. 1993. The importance of wildlife to Canadians: results from three national surveys. In Proceedings of the International Union of Game Biologists XXI Congress, Vol. 1. Edited by ID Thompson. Canadian Forest Service, Chalk River, Ontario. pp. 151-157.

Harshaw HW. 2008. British Columbia Species at Risk Public Opinion Survey 2008: final technical report. University of British Columbia Collaborative for Advanced Landscape Planning, Vancouver, BC. $136 \mathrm{p}$.

Hausman J. 2012. Contingent valuation: from dubious to hopeless. Journal of Economic Perspectives, 26: 43-56. doi:10.1257/jep.26.4.43.

Henderson AE, Reed M, and Davis SK. 2014. Voluntary stewardship and the Canadian Species at Risk Act: exploring rancher willingness to support species at risk in the Canadian Prairies. Human Dimensions of Wildlife, 19: 17-32. doi:10.1080/10871209.2013.819595.

Ipsos Reid. 2012. Three in five Canadians (62\%) say the federal government is doing too little to protect species at risk. New release, December 13, 2012. [online]: Available from http://www.ipsos-na. com/news-polls/pressrelease.aspx?id=5926.

Jackson EL. 1986. Outdoor recreation participation and attitudes to the environment. Leisure Studies, 5: 1-23. doi:10.1080/02614368600390011.

Jackson-Smith D, Kreuter U, and Krannich RS. 2005. Understanding the multidimensionality of property rights orientations: evidence from Utah and Texas ranchers. Society \& Natural Resources, 18: 587-610. doi:10.1080/08941920590959578.

James SM. 2002. Bridging the gap between private landowners and conservationists. Conservation Biology, 16: 269-271. doi:10.1046/j.1523-1739.2002.01039.x.

Kellert SR. 1996. The value of life. Island Press, Washington, DC. 263 p.

Kellert SR, and Berry JK. 1987. Knowledge and behaviors toward wildlife as affected by gender. Wildlife Society Bulletin, 15: 363-371.

Kerr JT, and Deguise I. 2004. Habitat loss and the limits to endangered species recovery. Ecology Letters, 7: 1163-1169. doi:10.1111/j.1461-0248.2004.00676.x.

Kirchhoff D, and Tsuji LJS. 2014. Reading between the lines of the 'Responsible Resource Development' rhetoric: the use of omnibus bills to 'streamline' Canadian environmental legislation. Impact Assessment and Project Appraisal, 32: 108-120. doi:10.1080/14615517.2014. 894673.

Knight AJ. 2008. "Bats, snakes and spiders, Oh my!" How aesthetic and negativistic attitudes, and other concepts predict support for species protection. Journal of Environmental Psychology, 28: 94-103. doi:10.1016/j.jenvp.2007.10.001.

Lorimer J. 2007. Nonhuman charisma. Environment and Planning D: Society and Space, 25: 911-932. doi:10.1068/d71j.

Lovett-Doust J, Biernacki M, Page R, Chan M, Natgunarajah R, and Timis G. 2003. Effects of land ownership and landscape-level factors on rare-species richness in natural areas of southern Ontario, Canada. Landscape Ecology, 18: 621-633. doi:10.1023/A:1026028017696. 
Matthews S, Pease SM, Gordon AM, and Williams PA. 1993. Landowner perceptions and the adoption of agroforestry practices in southern Ontario, Canada. Agroforestry Systems, 21: 159-168. doi:10.1007/BF00705227.

McCune JL, Harrower WL, Avery-Gomm S, Brogan JM, Csergo AM, Davidson LNK, et al. 2013. Threats to Canadian species at risk: an analysis of finalized recovery strategies. Biological Conservation, 166: 254-265. doi:10.1016/j.biocon.2013.07.006.

McDevitt-Irwin JM, Fuller SD, Grant C, and Baum JK. 2015. Missing the safety net: evidence for inconsistent and insufficient management of at-risk marine fishes in Canada. Canadian Journal of Fisheries and Aquatic Sciences, 72: 1596-1608. doi:10.1139/cjfas-2015-0030.

Mooers AO, Doak DF, Findlay CS, Green DM, Grouios C, Manne LL, et al. 2010. Science, policy, and species at risk in Canada. BioScience, 60: 843-849. doi:10.1525/bio.2010.60.10.11.

Nelson TE, and Oxley ZM. 1999. Issue framing effects on belief importance and opinion. The Journal of Politics, 61: 1040-1067. doi:10.2307/2647553.

Olive A. 2011. Can stewardship work for species at risk? A Pelee Island Case Study. Journal of Environmental Law and Practice, 22: 223-238.

Olive A. 2014. Land, stewardship, and legitimacy: endangered species policy in Canada and the United States. University of Toronto Press, Toronto, Ontario. 285 p.

Olive A, and McCune JL. 2017. Wonder, ignorance, and resistance: landowners and the stewardship of endangered species. Journal of Rural Studies, 49: 13-22. doi:10.1016/j.jrurstud.2016.11.014.

Otto S, McKee S, and Whitton J. 2013. Saving species at risk starts at the top. Where is our environment minister? The Globe and Mail, August 14, 2013.

Prugh LR, Sinclair ARE, Hodges KE, Jacob AL, and Wilcove DS. 2010. Reducing threats to species: threat reversibility and links to industry. Conservation Letters, 3: 267-276. doi:10.1111/ j.1755-263X.2010.00111.x.

Quartuch MR, and Beckley TM. 2014. Carrots and sticks: New Brunswick and Maine forest landowner perceptions toward incentives and regulations. Environmental Management, 53: 202-218. PMID:24281917. doi:10.1007/s00267-013-0200-z.

R Core Team. 2013. R: a language and environment for statistical computing. R Foundation for Statistical Computing, Vienna, Austria. [online]: Available from http://www.R-project.org/.

Raymond L, and Olive A. 2008. Landowner beliefs regarding biodiversity protection on private property: an Indiana case study. Society \& Natural Resources, 21: 483-497. doi:10.1080/ 08941920801905203.

Richardson L, and Loomis J. 2009. The total economic value of threatened, endangered and rare species: an updated meta-analysis. Ecological Economics, 68: 1535-1548. doi:10.1016/j. ecolecon.2008.10.016.

Schaffner BF. 2014. Does survey mode still matter? Findings from a 2010 multi-mode comparison. Political Analysis, 22: 285-303. doi:10.1093/pan/mpt025. 
Schrecker T. 2001. Using science in environmental policy: can Canada do better? In Governing the environment: persistent challenges, uncertain innovations. Edited by EA Parson. University of Toronto Press, Toronto, Ontario. pp. 31-72.

Sorice MG, Oh CO, Gartner T, Snieckus M, Johnson R, and Donlan CJ. 2013. Increasing participation in incentive programs for biodiversity conservation. Ecological Applications, 23: 1146-1155. PMID:23967582. doi:10.1890/12-1878.1.

Statistics Canada. 2013. Canadian internet use survey, 2012 [online]: Available from http://www. statcan.gc.ca/daily-quotidien/131126/dq131126d-eng.htm.

Sutherland B. 1997. Nature conservation on private land in Nova Scotia. Proceedings of the Nova Scotian Institute of Science, 41: 77-89.

Venter O, Brodeur NN, Nemiroff L, Belland B, Dolinsek IJ, and Grant JWA. 2006. Threats to endangered species in Canada. Bioscience, 56: 903-910. doi:10.1641/0006-3568(2006)56[903:TTESIC]2.0. $\mathrm{CO} ; 2$.

Vinge-Mazer SLT, and Ranalli MA. 2012. Rare plant rescue: conserving rare plant populations through voluntary stewardship. In Conserving plant biodiversity in a changing world: a view from northwestern North America. Edited by WJ Gibble, JK Combs, and SH Reichard. Seattle, Washington. p. 106.

Zaller J, and Feldman S. 1992. A simple theory of the survey response: answering questions versus revealing preferences. American Journal of Political Science, 36: 579-616. doi:10.2307/2111583. 